Research Article

\title{
Enhanced Fuzzy Delphi Method in Forecasting and Decision-Making
}

\author{
Majed G. Alharbi $\mathbb{D}^{1}$ and Hamiden Abd El- Wahed Khalifa $\mathbb{i D}^{1,2,3}$ \\ ${ }^{1}$ Department of Mathematics, College of Science and Arts, Methnab, Qassim University, Buraydah, Saudi Arabia \\ ${ }^{2}$ Department of Operations Research, Faculty of Graduate Studies for Statistical Research, Cairo University, Giza 12613, Egypt \\ ${ }^{3}$ Department of Mathematics, College of Science and Arts, Al-Badaya, Qassim University, Buraydah, Saudi Arabia
}

Correspondence should be addressed to Hamiden Abd El-Wahed Khalifa; ha.ahmed@qu.edu.sa

Received 21 May 2021; Revised 12 July 2021; Accepted 4 October 2021; Published 31 October 2021

Academic Editor: Bekir Sahin

Copyright ( $\odot 2021$ Majed G. Alharbi and Hamiden Abd El- Wahed Khalifa. This is an open access article distributed under the Creative Commons Attribution License, which permits unrestricted use, distribution, and reproduction in any medium, provided the original work is properly cited.

\begin{abstract}
The Delphi method is a process where subjective data are transformed into quasi-objective data using statistical analysis and are converged to stable points. The Delphi method was developed by the RAND Corporation at Santa Monica, California, and is widely used for longrange forecasting in management science. It is a method by which the subjective data of experts are made to converge using some statistical analyses. This article proposes a variation of the Delphi method using triangular fuzzy numbers, where the communication method with the experts is the same, but the estimation procedure is different. The utility of the method is illustrated by a numerical example.
\end{abstract}

\section{Introduction}

In the Delphi method, experts with high qualifications are first requested to give their opinions separately, without any intercommunication, regarding predicting and realizing certain events in science and technology. Then, a statistical analysis is conducted to assess these subjective data, and their first, second, and third quartiles are computed. This statistical information is transmitted to the experts. Furthermore, these new estimates are then analyzed, and the first, second, and third quartiles are recalculated. The new information is sent out to the experts once again, and this process of restoration is continued until the process converges to a reasonable stable solution. Grisham [1] provided project management students with an example of the Delphi research approach applied to a recent doctoral research thesis, reviewed the literature on the Delphi approach, and explained the research method tool. Many authors have dealt with the Delphi method such as Story et al. [2], Kauko and Palmroos [3], Skinner et al. [4], and Beiderbeck et al. and Lawnik and Banasik [5, 6]. Piecyk and McKinnon [7] reviewed applications of the method to the field of freight transport and logistics, assessed the usualness of Delphi- derived predictions of long-term freight, and associated environmental trends. They introduced a case study, the experience of a large two-round Delphi survey undertaken in the UK to elicit projections of long-term trends in a number of road freight and logistics variables. Revez et al. [8] demonstrated the transformative potential of combining participatory action research approaches with a modified Delphi method to understand energy transition issues, particularly beyond forecasting instruments.

In the literature, first of all, Zadeh [9] proposed the philosophy of fuzzy sets. Decision-making in a fuzzy environment, developed by Bellman and Zadeh [10], has been improved, enhancing the management of decision problems. Zimmermann [11] introduced fuzzy programming and linear programming with multiple objective functions. Then, several researchers have worked on fuzzy set theory. The theory and applications of fuzzy sets, systems, and fuzzy mathematical models were studied by many authors [12-19]. Cheng et al. [20] investigated a new fuzzy Delphi method (FDM) to fit membership functions and examined the stability of the process of the technique. Roy and Garai [21] used a triangular intuitionistic fuzzy number to introduce a new and improved version of the FDM. Moreover, Habibi 
et al. [22] applied the FDM to the single round for screening criteria. Hsu et al. [23] summarized the key courses in the education of construction engineers, where the evaluation aspects and index are established using the FDM. Ciptono et al. [24] classified and identified scientific research and analyzed the current literature on the FDM to gain a broad and detailed understanding of education.

Furthermore, He et al. [25] proposed a method to select the proper green supplier successfully. Huang et al. [26] used the FDM to identify the key input variables with the deepest influence on the prediction of peak particle velocity (PPV) based on the expert's opinions and applied the effective parameters on PPV in hybrid artificial neural network-based models, i.e., genetic algorithm, particle swarm optimization, imperialism competitive algorithm, artificial bee colony, and firefly algorithm, for the PPV prediction. Kabir and Sumi [27] proposed a new forecasting mechanism modeled by integrating the FDM with an artificial neural network technique to manage the demand with incomplete information. Many researchers have used the FDM in their works [28-30].

This article proposed a variation of the Delphi method using triangular fuzzy numbers, where the communication method with experts is the same, but the estimation procedure is different.

Having motivation from the above literature, in this study, a variation of the Delphi method using triangular fuzzy numbers, where the communication method with the experts is the same, but the estimation procedure is different, is studied.

The rest of the paper is outlined as shown in Figure 1.

\section{Preliminaries}

In order to easily discuss the problem, the basic rules and findings related to fuzzy sets, fuzzy numbers, triangular fuzzy numbers, and arithmetic operations are recalled.

Definition 1 (see [31]). Let $M=X_{1} \times X_{2} \times \ldots \times X_{n}$ be the Cartesian product, $\mu_{i}$ be the fuzzy set in $X_{i}$, and $f: X \longrightarrow Y$ be the mapping. Then, the fuzzy set $\widetilde{A}$ in $Y$ can be defined using the extension principle as follows:

$$
\tilde{A}(y)= \begin{cases}\operatorname{Sup}_{\left(x_{1}, \ldots, x_{n}\right) \in f^{-1}(y)} \min \left\{\mu_{1}\left(x_{1}\right), \ldots, \mu_{n}\left(x_{n}\right)\right\}, & f^{-1}(y) \neq \varnothing, \\ 0, & f^{-1}(y)=\varnothing .\end{cases}
$$

Definition 2 (see [31]). Let $\widetilde{A}$ and $\widetilde{B}$ be two fuzzy sets; the algebraic operations are defined as follows:

(1) Addition: $\widetilde{A}(+) \widetilde{B}$ :

$$
\mu_{\tilde{A}(+) \widetilde{B}}(z)=\operatorname{Sup}_{z=x+y} \min \left\{\mu_{A}, \mu_{B}\right\}, \quad x \in \widetilde{A}, y \in \widetilde{B} .
$$

(2) Subtraction: $\widetilde{A}(-) \widetilde{B}$ :

$$
\mu_{\tilde{A}(-) \widetilde{B}}(z)=\operatorname{Sup}_{z=x-y} \min \left\{\mu_{\tilde{A}}, \mu_{B}\right\}, \quad x \in \widetilde{A}, y \in \widetilde{B} .
$$

(3) Multiplication: $\widetilde{A}(.) \widetilde{B}$ :

$$
\mu_{\tilde{A}(.) \widetilde{B}}(z)=\operatorname{Sup}_{z=x . y} \min \left\{\mu_{\widetilde{A}}, \mu_{B}\right\}, \quad x \in \widetilde{A}, y \in \widetilde{B} .
$$

(4) Division: $\widetilde{A}(/) \widetilde{B}$ :

$$
\mu_{\tilde{A}(/) \widetilde{B}}(z)=\operatorname{Sup}_{z=x / y} \min \left\{\mu_{\tilde{A}^{\prime}}, \mu_{\tilde{B}}\right\}, \quad x \in \widetilde{A}, y \in \widetilde{B} .
$$

Definition 3 (see [9]; fuzzy number). Fuzzy number $\widetilde{F}$ is a fuzzy set with a membership function defined as follows. $\pi_{\tilde{F}}^{\sim}(x): \mathfrak{R} \longrightarrow[0,1]$, satisfying the following:

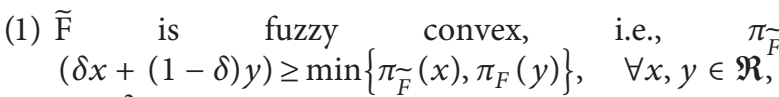
$; 0 \leq \delta \leq 1$

(2) $\widetilde{F}$ is normal, i.e., $\exists x_{0} \in \mathfrak{R}$ for which $\pi_{\widetilde{F}}\left(x_{0}\right)=1$

(3) $\operatorname{Supp}(\widetilde{F})=\left\{x \in \mathfrak{R}: \pi_{F}(x)>0\right\}$ is the support of $\widetilde{F}$

(4) $\pi_{\tilde{F}}(x)$ is upper semicontinuous, i.e., for each $\alpha \in(0,1)$, the $\alpha$-cut set $\widetilde{F}_{\alpha}=\left\{x \in \mathfrak{R}: \pi_{\widetilde{F}} \geq \alpha\right\}$ is closed

Definition 4 (see [32]). Fuzzy number $\widetilde{F}=(a, b, c)$ is called a triangular fuzzy number (TFN) if its membership function is given by

$$
\mu_{F}(x)= \begin{cases}0, & x<a, \\ \frac{x-a}{b-a}, & a \leq x \leq b, \\ \frac{c-x}{c-b} & b \leq x \leq c, \\ 0, & x \geq c,\end{cases}
$$

and illustrated by Figure 2 [15].

Definition 5. Let $\widetilde{F}=(a, b, c)$ and $\widetilde{G}=(e, f, g)$ be two triangular fuzzy numbers. The arithmetic operations on $\widetilde{F}$ and $\widetilde{G}$ are as follows:

(1) Addition: $\widetilde{F} \oplus \widetilde{G}=(a+e, b+f, c+g)$

(2) Subtraction: $\widetilde{F} \ominus \widetilde{G}=(a-g, b-f, c-e)$

(3) Inverse: $\widetilde{F}^{-1}=(1 / c),(1 / b),(1 / a)$

(4) Symmetric (image): $-(\widetilde{F})=(-c,-b,-a)$

\section{Notations and Remarks}

3.1. Notations. In the FDM, the following notations may be used:

$\left(P_{i}, Q_{i}, R_{i}\right)$ : sheaf of experts' opinion

$\left(\overline{P_{i}}, \overline{Q_{i}}, \overline{R_{i}}\right)$ : mean of the sheaf

$\delta\left(M_{i}, M_{j}\right)$ : normalized distance between the two triangular fuzzy numbers $M_{i}$ and $M_{j}$ 


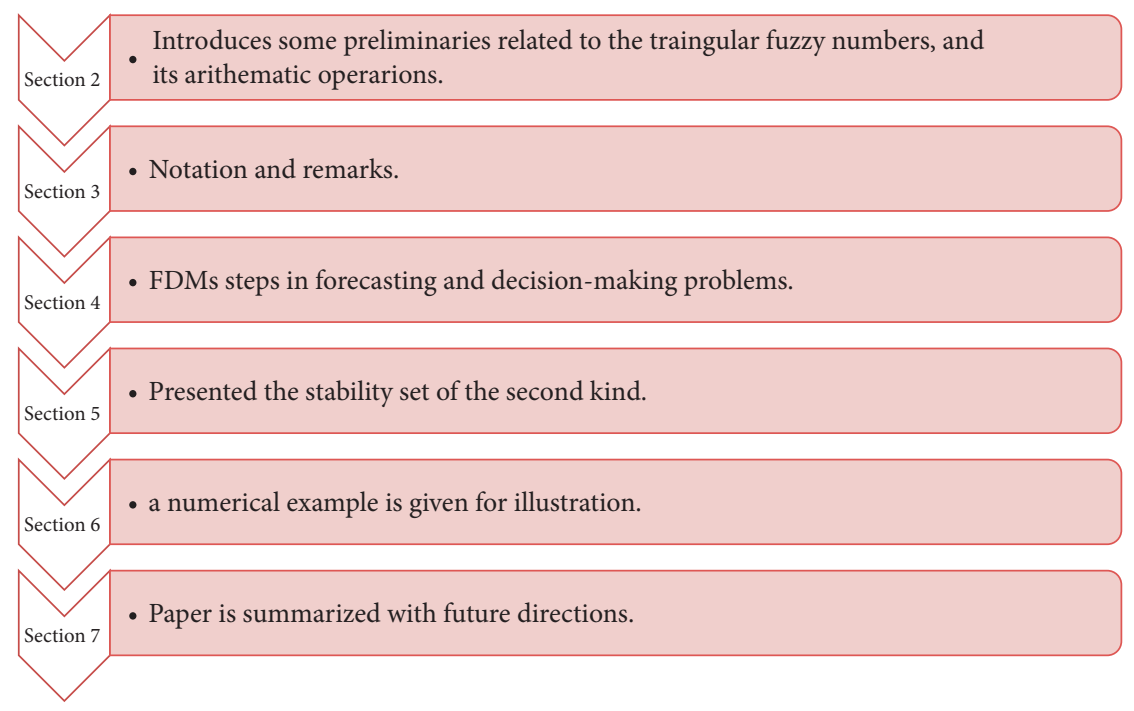

Figure 1: Outline of the paper.

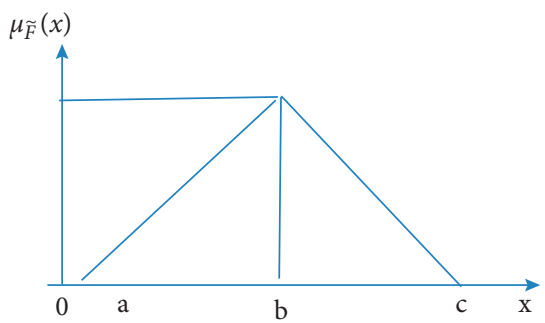

Figure 2: Triangular fuzzy number representation.

3.2. Remarks. The following important remarks should be noted [15]:

(i) A long-range forecasting problem must be considered an uncertain problem but not random. The direct use of the probabilistic methods is not suitable. The use of fuzzy numbers and fuzzy methods seems to be more compatible and well suited.

(ii) The experts use their individual competency and subjectivity, which is why we propose the concepts of fuzzy.

(iii) If an expert was asked the following question,

Consider the realization of a scientific or technological fact in the near future. What type of dates for its realization would you give? The expert will certainly be more comfortable answering this question using three types of dates: the earliest date, the maximum presumption date, and the latest date, rather than giving an answer regarding the probability of realization.

(iv) Using TFNs, it is easy for an expert to study the realization dates, which are nested within each other.

(v) The sheaf of fuzzy numbers concept is an aggregation process that appears to be very convenient for the objectification of various subjective opinions. (vi) Comparisons between expert answers using TFNs are simple, and the distance matrices can be easily computed. This matrix is a dissemblance relation decomposable into similarity relations. Using this approach, finding a nondisjunction subgroup of experts, who are favorable to studies in public opinion, is very convenient.

(vii) Many forecasts need multistage processes. By considering the partial and necessary realization, the critical path method can be applied to obtain the composite extremal dates.

\section{Fuzzy Delphi Method}

In this section, the steps of the application of the FDM can be explained as follows.

Step 1. The expert $i \in(1, n)$ is requested to give a possible realization date (the earliest date, the maximum presumption date, and the latest date) of the project using a TFN:

$$
\left(P_{1}^{i}, Q_{1}^{i}, R_{1}^{i}\right)
$$

where $i$ indicates the index attached to the expert and 1 indicates that this is the first phase of the forecasting process.

Step 2. The responses from $n$ experts from a sheaf are as follows:

$$
\left(P_{1}^{i}, Q_{1}^{i}, R_{1}^{i}\right), \quad i=\overline{1, n} .
$$

The mean of this TFN sheaf is then computed:

$$
\left(\overline{P_{1}}, \overline{Q_{1}}, \overline{R_{1}}\right) \text {. }
$$

Moreover, for each expert, the divergence is computed as follows:

$$
D_{i}=\left\{\overline{P_{1}}-P_{1}^{i}, \overline{Q_{1}}-Q_{1}^{i}, \overline{R_{1}}-R_{1}^{i}\right\}
$$


where these divergence numbers can be positive, null, or negative in sign. This information is then sent to each individual expert.

Step 3. Each expert now gives a new TFN:

$$
\left(P_{2}^{i}, Q_{2}^{i}, R_{2}^{i}\right) \text {. }
$$

Furthermore, the process, starting with phase 2, is repeated.

Step 4. If necessary, a study of partial group opinions is realized using the distance between the TFN and the decomposition of the dissemblance relations in the maximal subrelation of similarity. The information about these results (nonnominative) can be sent to interested experts.

Step 5. When the mean TFN becomes sufficiently stable (i.e., the mean TFN that fixed the solution and decision maker is satisfactory), the process is stopped. Of course, later, if necessary, or if important discoveries or realizations take place, the forecasting can be reevaluated by repeating the process outlined above.

\section{Numerical Example}

Consider a technological realization problem of a cognitive information processing computer in the near future. Let us request a group of 12 computer experts to give us a subjective estimation using TFNs to realize this new computing technology. The experts' estimations are listed in Table 1.

The computation from this sheaf gives the mean TFN:

$$
\left(\overline{P_{1}}, \overline{Q_{1}}, \overline{R_{1}}\right)=(2027.83,2034.17,2040.25)=(2027,2034,2040) .
$$

In Figure 3, by comparing $\left(\overline{P_{1}}, \overline{Q_{1}}, \overline{R_{1}}\right)$ with the sheaf $\left(P_{1}^{1}, Q_{1}^{1}, R_{1}^{1}\right)$, the divergence yields

$$
\begin{aligned}
& \overline{P_{1}}-P_{1}^{1}=2027-2024=+3 \\
& \overline{Q_{1}}-Q_{1}^{1}=2034-2032=+2, \\
& \overline{R_{1}}-R_{1}^{1}=2040-2049=-9 .
\end{aligned}
$$

This information is given to each expert, and each reconsiders his/her previous forecast and gives a new TFN, thus obtaining a new sheaf. This process is continued until a stable solution according to certain criteria is reached. Of course, the number of such iteration phases can be limited a priori. Many variations of this procedure are possible. For instance, the experts can be advised not to increase the divergence, but this is only a suggestion because an expert must give their own unbiased opinion.

Definition 6. The normalized distance between two TFNs is defined as follows:
TABLE 1: Sheaf of experts' opinions for the technological realization of the cognitive information processing computer.

\begin{tabular}{lccc}
\hline Expert no. & $\begin{array}{c}\text { Earliest } \\
\text { date }\end{array}$ & $\begin{array}{c}\text { Maximum presumption } \\
\text { date }\end{array}$ & $\begin{array}{c}\text { Latest } \\
\text { date }\end{array}$ \\
\hline 1 & 2024 & 2032 & 2049 \\
2 & 2021 & 2024 & 2000 \\
3 & 2029 & 2034 & 2039 \\
4 & 2021 & 2022 & 2023 \\
5 & 2029 & 2034 & 2044 \\
6 & 2024 & 2034 & 2039 \\
7 & 2039 & 2047 & 2049 \\
8 & 2024 & 2036 & 2042 \\
9 & 2024 & 2031 & 2036 \\
10 & 2037 & 2038 & 2049 \\
11 & 2039 & 2049 & 2049 \\
12 & 2023 & 2029 & 2034 \\
\hline
\end{tabular}

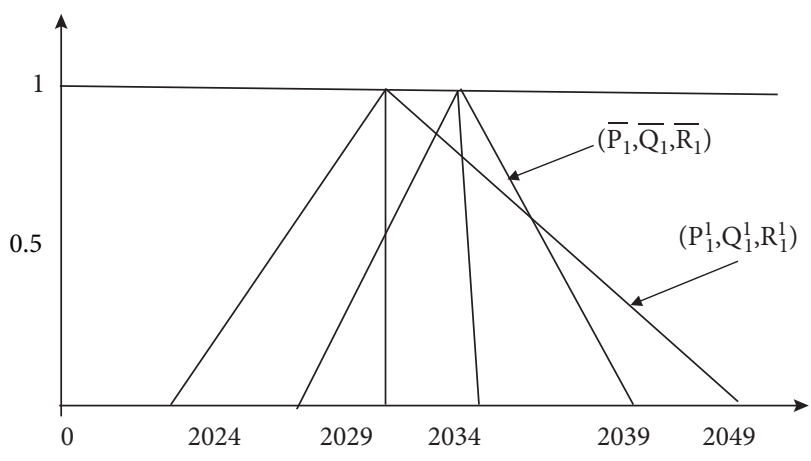

Figure 3: Comparison of a sheaf $\left(P_{1}^{1}, Q_{1}^{1}, R_{1}^{1}\right)$ with the mean $\left(\overline{P_{1}}, \overline{Q_{1}}, \overline{R_{1}}\right)$.

$$
\delta\left(M_{i}, M_{j}\right)=\frac{1}{2\left(\gamma_{2}-\gamma_{1}\right)}\left(\Delta_{l}\left(M_{i}, M_{j}\right)+\Delta_{r}\left(M_{i}, M_{j}\right)\right),
$$

where $M_{i}$ and $M_{j}$ are the TFNs given by experts $i$ and $j ; \Delta_{l}$ and $\Delta_{r}$ are the left and right distances, respectively; and $\gamma_{2}$ and $\gamma_{1}$ are arbitrary values at the right and left, respectively, chosen with the condition $\delta \in[0,1]$.

Using formula (14), the results of the computation are inserted in Table 2 for the arbitrary values of $\gamma_{1}=2021$ and $\gamma_{2}=2049$.

As shown in Table 2, we see that the minimum distance is $\delta(7,11)=0.03$, and the maximum distance is $\delta(4,11)=0.87$.

Let us assume that we are interested in a pair of experts for whom the distance $\delta\left(M_{i}, M_{j}\right) \leq 0.15$. The matrix in Table 3 gives these pairs. The corresponding pairs are shown in Figure 4.

A direct examination of Figure 4 gives the maximum subrelations of similarity. For example, we have the following: 
TABLe 2: Distances of $\delta\left(M_{i}, M_{j}\right)$.

\begin{tabular}{|c|c|c|c|c|c|c|c|c|c|c|c|c|}
\hline$\delta\left(M_{i}, M_{j}\right)$ & 1 & 2 & 3 & 4 & 5 & 6 & 7 & 8 & 9 & 10 & 11 & 12 \\
\hline 1 & 0 & 0.36 & 0.16 & 0.43 & 0.12 & 0.16 & 0.4 & 0.13 & 0.13 & 0.13 & 0.43 & 0.19 \\
\hline 2 & & 0 & 0.35 & 0.07 & 0.4 & 0.44 & 0.76 & 0.37 & 0.23 & 0.58 & 0.8 & 0.16 \\
\hline 3 & & & 0 & 0.42 & 0.04 & 0.017 & 0.41 & 0.10 & 0.12 & 0.23 & 0.44 & 0.18 \\
\hline 4 & & & & 0 & 0.47 & 0.51 & 0.83 & 0.46 & 0.30 & 0.60 & 0.87 & 0.24 \\
\hline 5 & & & & & 0 & 0.13 & 0.34 & 0.09 & 0.16 & 0.18 & 0.40 & 0.23 \\
\hline 6 & & & & & & 0 & 0.33 & 0.07 & 0.21 & 0.26 & 0.35 & 0.27 \\
\hline 7 & & & & & & & 0 & 0.39 & 0.53 & 0.17 & 0.03 & 0.59 \\
\hline 8 & & & Symmetry & & & 0 & 0.14 & 0.21 & 0.44 & 0.20 & & \\
\hline 9 & & & & & & & & & 0 & 0.35 & 0.57 & 0.06 \\
\hline 10 & & & & & & & & & & 0 & 0.21 & 0.41 \\
\hline 11 & & & & & & & & & & & 0 & 0.72 \\
\hline 12 & & & & & & & & & & & & 0 \\
\hline
\end{tabular}

TABle 3: Pair of experts with arbitrary $\delta \leq 0.15$.

\begin{tabular}{|c|c|c|c|c|c|c|c|c|c|c|c|c|}
\hline$\delta_{i j} \leq 0.15$ & 1 & 2 & 3 & 4 & 5 & 6 & 7 & 8 & 9 & 10 & 11 & 12 \\
\hline 1 & 1 & & & & 1 & & & 1 & 1 & 1 & & \\
\hline 2 & & 1 & & 1 & & & & & & & & \\
\hline 3 & & & 1 & & 1 & & & 1 & 1 & & & \\
\hline 4 & & & & 1 & & & & & & & & \\
\hline 5 & & & & & 1 & 1 & & 1 & & & & \\
\hline 6 & & & & & & 1 & & 1 & & & & \\
\hline 7 & & & & & & & 1 & & & & 1 & \\
\hline 8 & & & & & & & & 1 & 1 & & & \\
\hline 9 & & & & & & & & & 1 & & & 1 \\
\hline 10 & & & & & & & & & & 1 & & \\
\hline 11 & & & & & & & & & & & 1 & \\
\hline 12 & & & & & & & & & & & & 1 \\
\hline
\end{tabular}

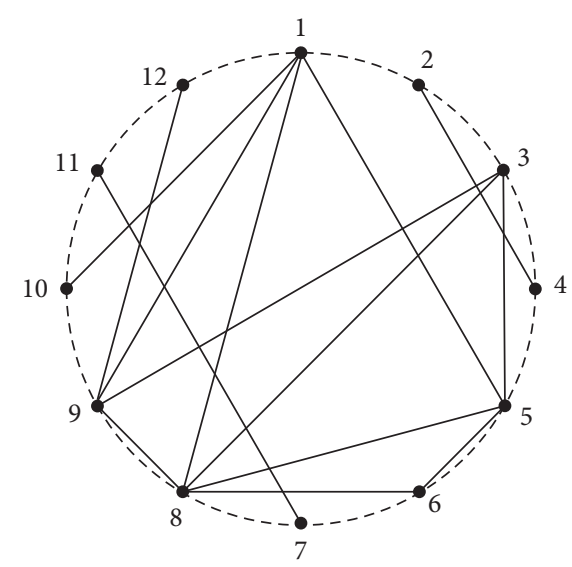

Figure 4: Pairs of experts with $\delta \leq 0.20$.

If we consider, for instance, experts $(1,8,9)$ and $(3,8,9)$, we find that $\delta(1,3)=0.16$. We can assume, therefore, that experts $(1,3,8,9)$ have given almost the same estimation. A similar situation appears with $(1,5,8),(3,8,9)$, and $(1,3,8,9)$ that have almost the same estimation. Therefore, we can aggregate experts $(1,3,5,8,9)$.

\section{Discussion of the Results}

If we consider $\delta \leq 0.20$, we find this aggregation directly. In fact, using a convenient algorithm, the problem can be studied with various values of $\delta$, that is, $\delta \leq 0.2,0.25, \ldots$. If we wish to consider the similarity problem, then a value smaller than $(1-\delta)$ gives the level of similarity, which is an important point in any a posteriori discussion between experts. The maximal subrelations of similarity in a resemblance relation play the same role as classes in a similarity relation. The second one is always disjointed, but this is not the case for the first one.

\section{Conclusions and Future Works}

A variation of the Delphi method using TFNs has been proposed, in which the method of communication with experts is the same, but the estimation procedure is different. Of note, in many cases, a forecasted success requires various steps of operations; therefore, using the critical path method for forecasting is more efficient in such cases. In fact, many other ways can be used for forecasting using fuzzy numbers, which we may investigate in the future. Future work may include the further extension of this study to other fuzzy-like structures, i. e., interval-valued fuzzy set, intuitionistic fuzzy set, Pythagorean fuzzy set, spherical fuzzy set, picture fuzzy set, neutrosophic set, etc., with more discussion on realworld problems.

\section{Data Availability}

No data were used to support this study.

\section{Conflicts of Interest}

The authors declare no conflicts of interest.

\section{References}

[1] T. Grisham, "The Delphi technique: a method for testing complex and multifaceted topics," International Journal of Managing Projects in Business, vol. 2, no. 1, pp. 112-130, 2009.

[2] V. Story, L. Hurdley, G. Smith, and J. Saker, "Methodological and practical implications of the Delphi technique in marketing decision-making: a Re-assessment," The Marketing Review, vol. 1, no. 4, pp. 487-504, 2000.

[3] K. Kauko and P. Palmroos, "The Delphi method in forecasting financial markets- an experimental study," International Journal of Forecasting, vol. 30, no. 2, pp. 313-327, 2014. 
[4] R. Skinner, R. R. Nelson, W. W. Chin, and L. Land, "The Delphi method research strategy in studies of information systems," Communications of the Association for Information Systems, vol. 37, no. 2, pp. 31-63, 2015.

[5] D. Beiderbeck, N. Frevel, H. A. Von Der Gracht, S. L. Schmidt, and V. M. Schweitzer, "Preparing, conducting, and analyzing Delphi surveys: cross-disciplinary practices, new directions, and advancements," Methods (Orlando), vol. 8, Article ID 101401, 2021.

[6] M. Lawnik and A. Banasik, "Delphi method supported by forecasting software," Information, vol. 11, no. 2, p. 65, 2020.

[7] M. I. Piecyk and A. C. McKinnon, "Application of the Delphi method to the forecasting of long- term trends in road freight, logistics and related $\mathrm{CO}_{2}$ emissions," International Journal of Transport Economics, vol. 40, no. 2, pp. 241-266, 2013.

[8] A. Revez, N. Dunphy, C. Harris, G. Mullally, B. Lennon, and C. Gaffney, "Beyond forecasting: using a modified Delphi method to build upon participatory acton research in developing principles for a just and inclusive energy transition," International Journal of Qualitative Methods, vol. 19, pp. 1-12, 2020.

[9] L. A. Zadeh, "Fuzzy sets," Information and Control, vol. 8, no. 3, pp. 338-353, 1965.

[10] R. E. Bellman and L. A. Zadeh, "Decision-making in a fuzzy environment," Management Science, vol. 17, no. 4, pp. B-141, 1970.

[11] H.-J. Zimmermann, "Fuzzy programming and linear programming with several objective functions," Fuzzy Sets and Systems, vol. 1, no. 1, pp. 45-55, 1978.

[12] Y. Badulescu, A.-P. Hameri, and N. Cheikhrouhou, "Evaluating demand forecasting models using multi-criteria decision-making approach," Journal of Advances in Management Research, 2021, ahead-of-print.

[13] D. Dubois and H. Prade, Fuzzy Sets and Systems: Theory and Applications, Academic Press, New York, NY, USA, 1980.

[14] J. Guo, C.-J. Chang, Y. Huang, and K.-P. Yu, "A fuzzy-decomposition grey modeling procedure for management decision analysis," Mathematical Problems in Engineering, vol. 2021, Article ID 6670196, 6 pages, 2021.

[15] A. Kaufmann and M. M. Gupta, Fuzzy Mathematical Models in Engineering and Management Science, Elsevier Science Publishing Company INC, New York, NY, USA, 1988.

[16] Z. K. Nemaa and G. K. Aswed, "Forecasting construction time for road projects and infrastructure using the fuzzy PERT method," IOP Conference Series: Materials Science and Engineering, vol. 1076, no. 1, Article ID 012123, 2021.

[17] F. Tahriri, M. Mousavi, S. Hozhabri Haghighi, and S. Zawiah Md Dawal, "The application of fuzzy Delphi and fuzzy inference system in supplier ranking and selection," Journal of Industrial Engineering International, vol. 10, no. 3, p. 66, 2014.

[18] H.-C. Tsai, A.-S. Lee, H.-N. Lee, C.-N. Chen, and Y.-C. Liu, "An application of the fuzzy Delphi method and fuzzy AHP on the discussion of training indicators for the regional competition, Taiwan National Skills competition, in the trade of joinery," Sustainability, vol. 12, no. 10, p. 4290, 2020.

[19] E. Vercher, A. Rubio, and J. D. Bermúdez, "Fuzzy prediction intervals using credibility distributions," Engineering Proceedings, vol. 5, no. 1, p. 51, 2021.

[20] P.-T. Cheng, L.-C. Huang, and H.-J. Lin, “The fuzzy Delphi method via fuzzy statistics and membership function fitting and an application to the human resources," Fuzzy Sets and Systems, vol. 112, no. 3, pp. 511-520, 2000.
[21] T. K. Roy and A. Garai, "Intuitionistic fuzzy Delphi method: more realistic and iterative forecasting tool," Notes on Intuitionistic Fuzzy Sets, vol. 18, no. 2, pp. 37-50, 2012.

[22] A. Habibi, F. F. Jahantigh, and A. Sarafrazi, "Fuzzy Delphi technique for forecasting and screening items," Asian Journal of Research in Business Economics and Management, vol. 5, no. 2, pp. 130-143, 2015.

[23] W.-L. Hsu, L. Chen, L. Chen, and H.-L. Liu, "The application fuzzy Delphi method to summarize key factors in the education of construction engineers," in Proceedings of the 2nd Eurasian Conference on Educational Innovations and Applications- Tijus Meen, Chang, Singapore, January 2019.

[24] A. Ciptono, s. Setiyono, F. Nurhidayati, and R. Vikaliana, "Fuzzy Delphi method in education: a mapping," Journal of Physics: Conference Series, vol. 1360, no. 1360, Article ID 012029, 2019.

[25] X.-G. Xu, H. Shi, L.-J. Zhang, and H. C. Liu, "Green supplier evaluation and selection with an extended MABAC method under the heterogeneous information environment," Sustainability, vol. 11, no. 23, p. 6616, 2019.

[26] J. Huang, M. Koopialipoor, and D. J. Armaghani, "A combination of fuzzy Delphi method and hybrid ANN-based systems to forecast ground vibration resulting from blasting," Scientific Reports, vol. 10, no. 1, Article ID 19397, 2020.

[27] G. Kabir and R. S. Sumi, "Integrating fuzzy Delphi method with artificial neural network for demand forecasting of power engineering company," Management Science Letters, vol. 2, no. 5, pp. 1491-1504, 2012.

[28] Y.-C. Chiang and H.-Y. Lei, "Using expert decision-making to establish indicators of urban friendliness for walking environments: a multidisciplinary assessment," International Journal of Health Geographics, vol. 15, no. 1, pp. 15-40, 2016.

[29] A. Garai and T. Kumar, "Weighted intuitionistic fuzzy Delphi method," Journal of Global Research in Computer Science, vol. 4, no. 7, pp. 38-42, 2013.

[30] J. Heidary Dahooie, A. R. Qorbani, and T. Daim, "Providing a framework for selecting the appropriate method of technology acquisition considering uncertainty in hierarchical group decision-making: case Study: interactive television technology," Technological Forecasting and Social Change, vol. 168, Article ID 120760, 2021.

[31] B. Lee and Y. Yun, "The pentagonal fuzzy numbers," Journal of the Chungcheong Mathematical Society, vol. 27, no. 2, 2014.

[32] M. C. J. Anand and J. Bharatraj, "Theory of triangular fuzzy number," in Proceedings of the NCATM, Kharghar, India, March 2017. 